\title{
Adapting Design Principles of Traditional Courtyard Housing for Future Urban Design
}

\author{
Soroush Nikeghbali ${ }^{1}$ \\ ${ }^{1} \mathrm{PhD}$ in Urban Design, Oxford Brookes University, UK \\ Correspondence: Soroush Nikeghbali, PhD in Urban Design, Oxford Brookes University, UK. E-mail: \\ soroushnikeghbali@yahoo.com
}

Received: July 23, 2017

Accepted: October 11, $2017 \quad$ Online Published: November 29, 2017

doi:10.5539/jsd.v10n6p200

URL: https://doi.org/10.5539/jsd.v10n6p200

\begin{abstract}
Most cities in recent decades have copied the modern type of architecture and urban design of the western countries. Modern cities in different regions of the world have been relatively developed with similar urban form types. In this research, it has been suggested to investigate the traditional or vernacular architecture and to propose new design principles based on the historic shape of cities. Thus the paper has been concentrated on vernacular architecture of traditional Iranian cities. The research has been focused on analysing the vernacular architecture of this country and to define the main traditional design principles in scale of urban fabric particularly in residential neighbourhoods. These principles have been adapted to be applicable for the contemporary life style and condition of the Iranian cities. The design proposal has been assessed via an inquiry by design process in order to understand the feasibility and adequacy of the suggested design principles. This research can show the methodology of learning from the traditional architecture and urban design to make new distinctive urban forms. Such urban forms create distinguished local identity for Iranian residential urban fabrics.
\end{abstract}

Keywords: courtyard housing, Iranian architecture, urban design, climate, culture

\section{Introduction}

The research approach in this paper is to analyse the traditional architecture and urban design of the country and identify the main design principles related to these historic urban forms and finally adapt these principles for the contemporary condition of Iranian cities. In order to conduct in depth research in such field, the area of investigation has been focused just on the residential neighbourhoods in cities of Iran with traditional type of housing. The shape of the house, as the smallest grain of the city form, has a fundamental spatial impact on the overall shape of the city. This research aims to explore on new types of housing and residential neighbourhoods that can be designed based on the vernacular architecture of the country, precisely responding to the current local condition of Iranian cities and citizens.

The main research method here is inquiry by design. Based on the theoretical discussion of the paper a design scheme is proposed; and then the design proposal was evaluated via focus group discussion. The new types of housing are designed and evaluated for this particular locality. Such new types of housing can be applied to the neighbourhoods, and finally shape new urban form types which are designed with a local distinctive identity.

The study approach is based on observation of traditional urban form. The outcome of this study has been categorised in two main dimensions of climatic and cultural issues. Regarding climatic issues, the research focuses on the natural features and climatic condition of the region, which has had spatial impact on buildings and the urban form. Residential building has been always developed as a shelter to make a better microclimate for living and prevent natural effects like intensive sunlight or wind. The diversity of natural environment has major impact on the variety of architecture and urban form of countries. The environmental factors also have great influence on the shape of houses and cities in Iran. The second main category of the study concerns the cultural issues. Iran has been part of the Islamic region of the world for more than a thousand years (Hillenbrand, 1994). The religion has made a specific life style for Iranian citizens. Such lifestyle have also had spatial impact on the shape of houses and the city. In this research the cultural issues have been divided into three main sub-categories of privacy, social cohesion and family life style.

Climate and cultural influences has shaped the form of traditional houses and consequently shaped the traditional 
city. Each of these spatial impacts will be identified and will be assessed based on the contemporary urban design principles to understand whether these traditional designs may be applicable for contemporary cities. Based on this, the traditional design principles will be adapted for contemporary housing.

\section{Climatic Issues}

Ghobadian (1998) points out that the majority of land in Iran is located in hot and dry climate. Many of Iranian cities have been developed near the hot desert, which shapes two third of land in the country. One of the main climatic features in this region is the significant difference between the day and night temperature and, as a result, most Iranian cities have very hot days and very cold nights (Ghobadian, 1998; Norton, 1997).

\subsection{Climatic Issues and Spatial Implication on House}

The common design solution for such climate of the Middle East region has usually been the Central Courtyard Housing (Ghobadian, 1998). This type of house contains a courtyard in the middle and the living spaces surrounding it. Normally all living spaces face to this central courtyard (figure 2). The courtyard usually has a few trees and a small pool. This open space is usually in the shade and therefore provides a cooler microclimate for the house. All the living spaces face this cool open space. Chow and Chastain (1997) describe this climatic benefit of central courtyard house in another way:

"Cold night time air from high above the courtyard, heavier than warm air, sinks into the courtyard and replaces slightly warmer air that has accumulated there

During the day and which is unable to escape because the ambient day time air temperature above the courtyard is warmer."

As the central courtyard houses face inward, they can be joined at their external perimeter (figure 2). This way the least amount of the building area will be exposed to the direct sunlight (Fathy, 1986). The main concept is to "minimize the amount building exposed to direct solar radiation, thus reducing the total heat gained" (Kheirabadi, 1991: 22).

\subsection{Climatic Issues and Spatial Implication on City}

It can be stated that there is a significant difference between the urban form in Middle Eastern cities and European cities. As evidence, in order to generally define the overall characteristic of European cities, it can be assumed that these cities have been shaped by perimeter blocks with a group of back gardens in the middle which receive direct sunlight during the day. However, as it appears from satellite views, the majority of Middle East cities are relatively shaped by courtyard houses with separated small shaded open spaces (figure 3 ). The open spaces have a smaller size than the European types and have been separated by the living spaces. Consequently, the European cities have been designed to receive maximum sunlight but the Middle East cities have been designed to provide maximum shaded spaces. Ghobadian (1998) and Kheirabadi (1991) acknowledge this viewpoint, as they describe the characteristic of Iranian traditional cities and mention that these cities usually have been designed by narrow streets with tall walls to increase the shaded surface of the street (figure 1). Some parts of the street are even covered by roofs or living spaces on top of the street (Roaf, 1997). Moreover, the streets are rarely designed in a straight line and the street pattern tends to be designed in a semi-organic shape. Kheirabady (1991) presumed that the main reason for making many turns or twists in the shape of the street is to reduce the speed of hot and dusty winds from the desert. However, it can also be pointed out that these changes in direction of streets make a different range of shadow and light spaces in the street and therefore provide light winds on microclimate scale. The light winds help ventilate and reduce the temperature in the street. 


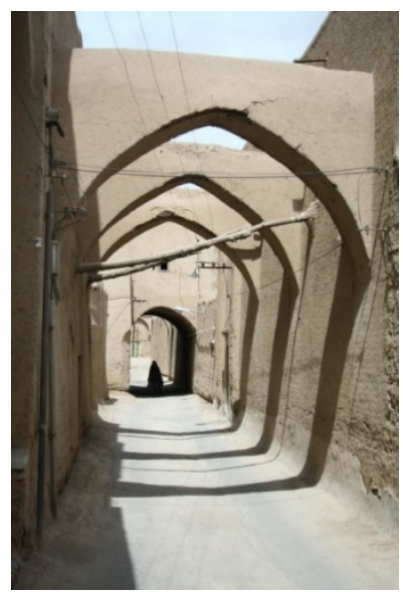

Figure 1. A street in yazd city: Narrow streets with tall walls are used to make more shaded spaces. Morover some part of the street has been covered to increase these shaded spaces

\subsection{Adaptation for Contemporary Cities}

During the 20th century the Iranian cities have been changed and mostly the European urban forms have been copied for new developments in the city (Madanipour, 1998). Figure 3 demonstrates a comparison between European and Iranian traditional urban block. The new developments in residential neighbourhoods of Iran commonly contain linear semi-perimeter blocks and the streets such as the European blocks; Open spaces have become wider and larger than the traditional urban form. As a result of this morphologic change, the new large scale open spaces are not as comfortable as the traditional ones in climatic terms.

It is apparent that the perimeter block has many benefits. Bentley et al. (1985) emphasise that this type of block makes clear separation between the private and public spaces and makes maximum active edges for the street. Hence, such a type of design helps security and liveability within the urban areas. However, on the other hand, the concentration of open spaces, in the middle of perimeter blocks, is not sufficient for the hot and dry climate of Iranian cities. It can be suggested that the best solution tends to be a new type of perimeter block which contains small and separated private open spaces such as courtyards (figure 4). These new courtyards provide more shaded space and consequently are more comfortable for the hot climate of Iranian cities.

The same concept can be proposed for the public spaces and streets. The public spaces should be designed on a small scale and with high rise surrounding buildings in order to reduce direct sunlight on the open space. Additionally, it can be stated that the streets are better designed with more shaded spaces and in narrow shape.

In addition, since the new cities have higher density and height of buildings compared with traditional cities, it can be assumed that increasing the height of buildings helps to increase the shaded space in the street and, therefore, there is more opportunity to widen the street. Furthermore, high dense trees tend to be helpful for increasing the amount of shadow on street. The main point is to provide maximum shaded open spaces for the city. This open space may be private as a courtyard or public like a street.

Furthermore, designing covered or semi-open spaces in the street can help to make better microclimatic conditions for the urban spaces. Specifically, in narrow streets, there are opportunities to make bridges or roofs to make more shaded open space. Such semi open spaces can also be used for the entrance space of houses. Moreover, using protrusion and depression in the elevation of houses helps to make more shades on exterior surfaces of the building and reduce sunlight absorption. In this way, designing balconies and window shades can be helpful. 

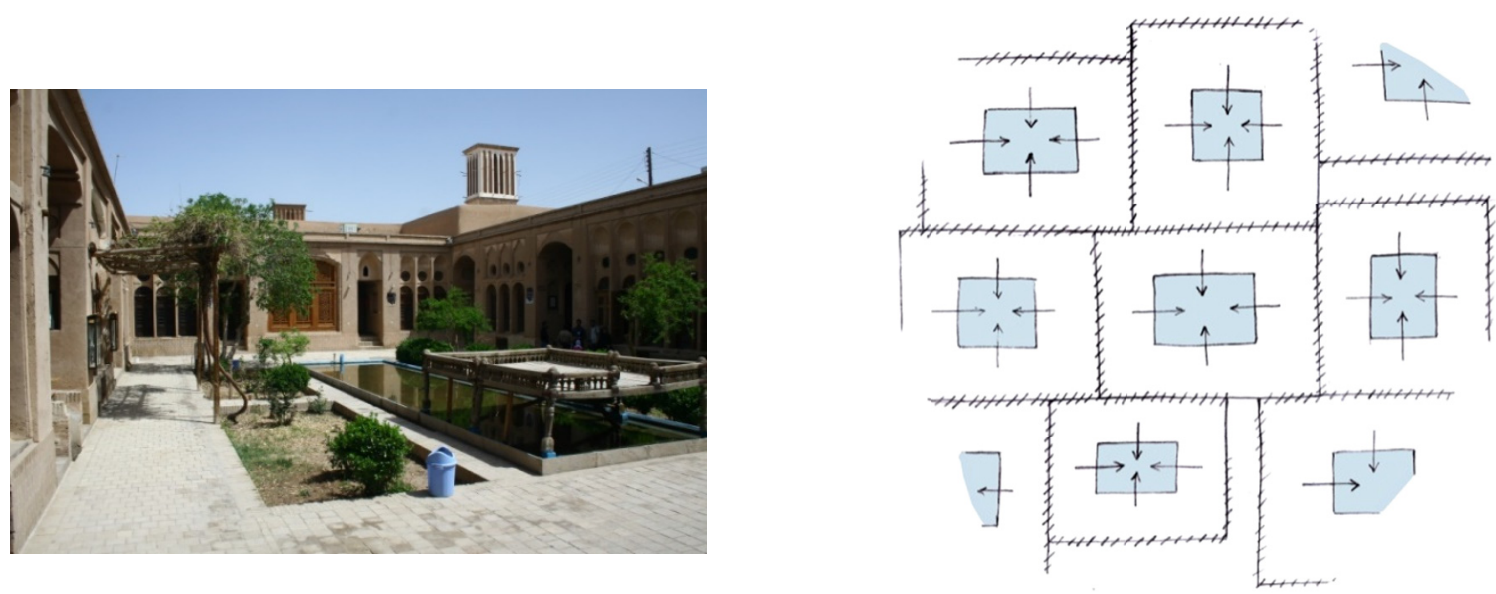

Figure 2. All living spaces face to the courtyards and the external façades have been attached to the next houses
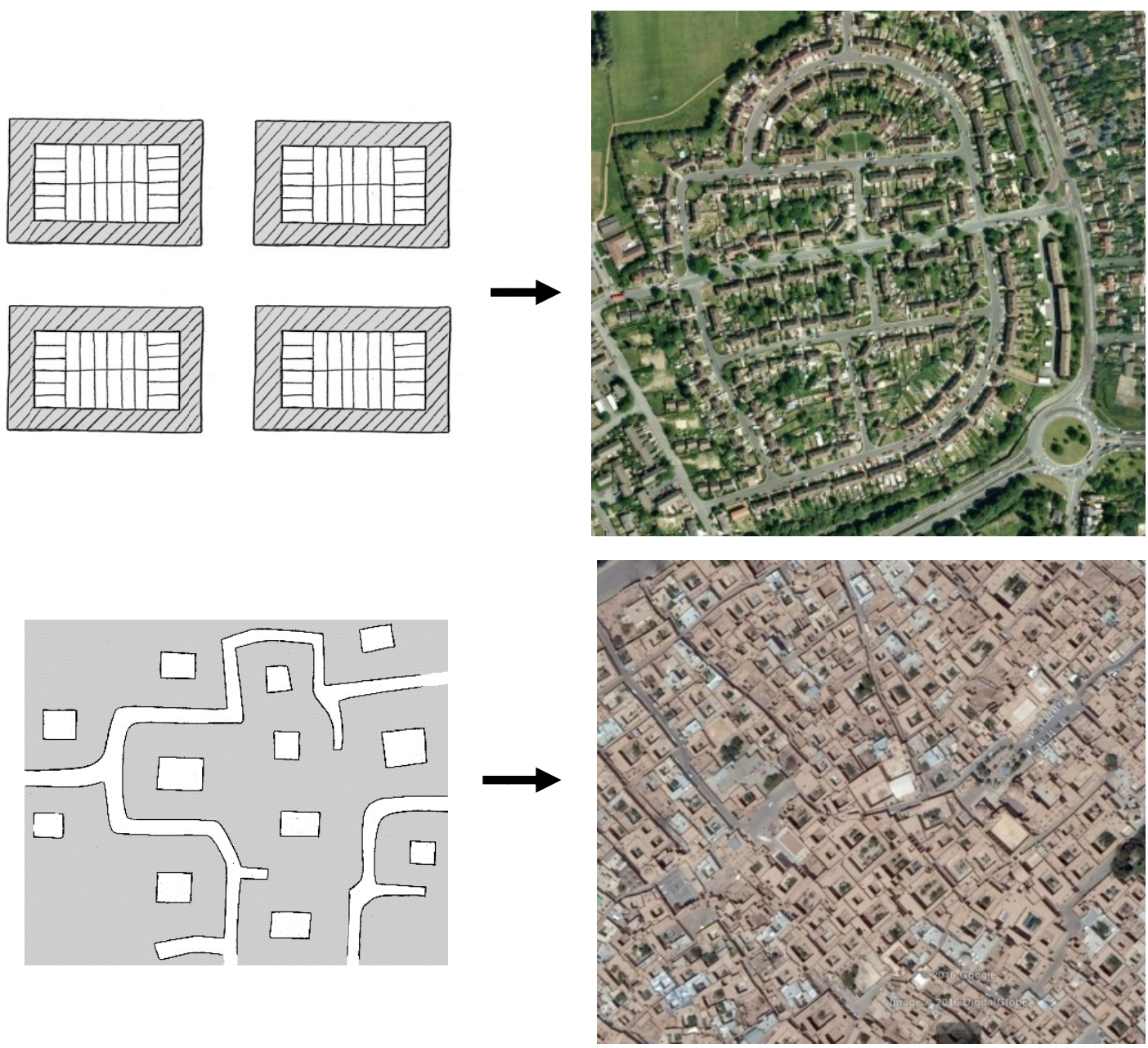

Figure 3. Comparing urban blocks types. Top left: European Block; top right: Oxford City; bottom left: Iranian traditional urban form; bottom right: Yazd city in Iran 

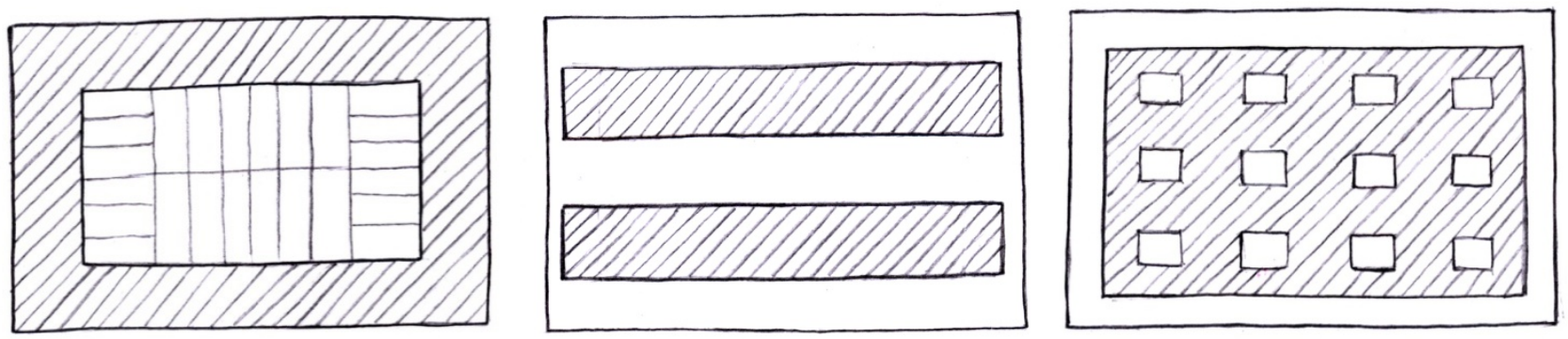

Figure 4. Proposed new type of block compared with existing types. Left: European block shape; middle: Contemporary Iranian block shape; right: proposed new type of block for hot and dry climate

\section{Cultural Issues}

\subsection{Privacy}

\subsubsection{Privacy in Traditional House}

Iran has been an Islamic country for more than a thousand years. Hence the Islamic rules and belief system shape a major part of Iranian culture and life style. As a part of this Islamic culture, the privacy of the family life has been emphasized in the social rules. As a result of this cultural feature, the privacy of houses and private space has been enhanced (Madanipour, 1998, Hakim 1997) and there is a distinct separation between the private and public space. Based on such consideration of privacy in family life, a main characteristic of traditional housing in Islamic countries such as Iran is the Inward Architecture (Pirnia, 2007).

Although it has been addressed that the living spaces in traditional houses usually face to the central courtyard because of the climatic issues, this typology of building also provides better privacy for the residents. The general shape of traditional houses shows that usually there is no view from street or other surrounding houses onto the private spaces (Zamani, 2010) (see figure 5 and 6). The central courtyard, as the private open space, cannot be seen from the outside. Living areas of the house just have windows facing the courtyard and the windows are rarely opened to the street and public space.

Demand for privacy also has spatial impact on the shape of the entrance of houses. The entrance is the place of linking public to private space. The entrance usually has the role of a filter between inside and outside of the house and usually has been designed as long corridors or covered passageways (Oliver, 1997) which allows limited view to the private spaces of the house. Even after the entrance section, there is a separation between the space for the guests and the family space (Pirnia 2004).

\subsubsection{Privacy in Traditional City}

As a result of inward architecture and limited windows of houses facing towards public space, the exterior façade of buildings are usually just soiled walls without any window. This shape of the exterior façade creates an inactive edge for the streets and therefore another main characteristic of traditional Iranian cities is the inactive edge of streets façade (figure 6).

The role of privacy has been also demonstrated in the street pattern of traditional cities. One of the main significant features of these traditional cities, which is pointed out in various literature (for example: Madanipour, 1998; Kheirabadi, 1991) is the hierarchy of streets. The main streets are the shopping streets, which are called Bazaar, and then there is a hierarchy of street which ends to the cul de sacs or blind alley. This hierarchy of streets and specifically regular use of blind alleys helps to reduce public view of small streets and also reduces traffic of strangers in the residential neighbourhoods, which improves the privacy and security of the area.

\subsubsection{Adaptation for Contemporary Cities}

As mentioned above, the new contemporary cities of Iran are usually designed with four or five storey flats with a front or back garden. However, as Madanipour (1998) argues and evidence shows, this type of housing would not provide sufficient privacy which Iranian citizens demand. The new flats do not have the privacy of courtyard houses, particularly in the private open space (back garden). The back garden should be used by more than one family and therefore the privacy of family life cannot be achieved in such common open spaces. Therefore, these gardens are rarely used by the residents (Madanipour, 1998) and somehow turned to leaved spaces. 
It is apparent from this evidence that the privacy of the house and its open space is still an important issue for this society. It seems that the courtyard housing can still make more privacy for families and make more useable private open space for such a culture. However, it can be argued that the low rise characteristic of traditional housing cannot respond to the demand for high dense housing in contemporary cities. One of the main solutions which this research applies for this conflict is to design courtyard houses in multi stories. In this way each house can have its own private courtyard and the density of neighbourhood can also be increased in order to reach the standards of contemporary cities. The feasibility of this idea will be investigated through "inquiry by design" method (Zeisel, 2006) in section 4 of this paper.

The other important impact of privacy on the traditional city was the inactive edge of the streets. However active edges have a fundamental role for safety and security of the public space (Barton, 2003; English Partnership, 2007). Jacob (1961) states that visual supervision or surveillance of the public space from adjacent houses helps improve the safety of the urban area. Hence the inactive edge of the traditional cities, which was designed based on privacy aspects, may reduce the safety of the street. Therefore, it is important to make more active edges for the new developed streets. However, the sufficient level of privacy can be gained by other design solutions.

Another main feature of traditional cities, which can be adapted for contemporary urban areas, is the hierarchy of streets and the use of cul de sacs. Cul de sacs can improve the privacy and security of the neighbourhood areas and this benefit of the cul de sacs have even been addressed in contemporary urban design (for example: Barton, 2003). However, designing cul de sacs can reduce the permeability and connectivity of the street pattern, as Bentley et al. (1985) state that this quality is one of the fundamental dimensions of a responsive urban environment. However, it can be argued that, based on the benefits of cul de sacs in this cultural context, there should be a balance between improving permeability of street pattern and enhancing the privacy or security by designing cul de sacs for the residential neighbourhoods.

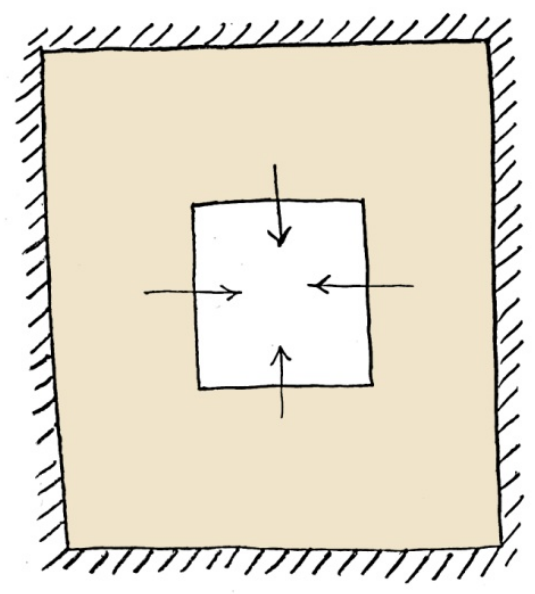

Figure 5. Traditional houses have inward architecture. All living spaces face to the middle courtyard and usually the external façade has no window

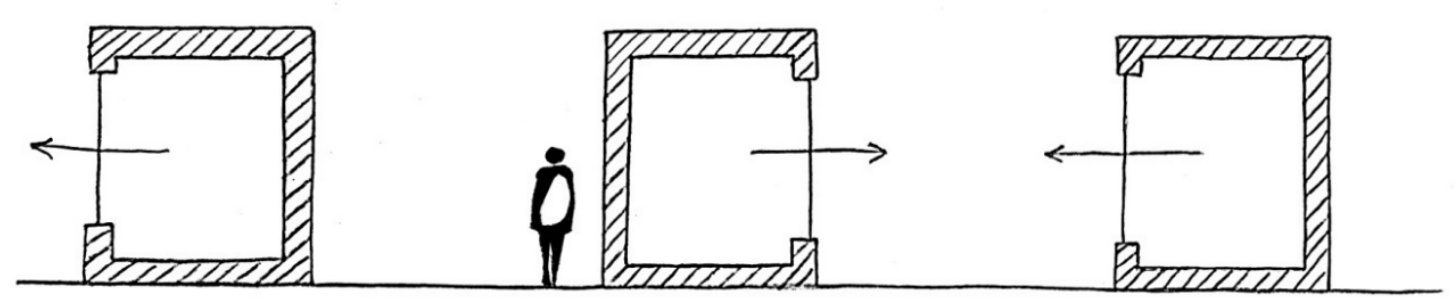

Figure 6. Windows usually open to the central courtyard but not to the street 


\subsection{Social Cohesion}

As the social cohesion issue is more about life of citizens out of the house, this issue can be discussed simply on the scale of public space and city.

\subsubsection{Social Cohesion in the City}

Another main feature of Islamic Iranian culture is the importance of taking care of the comfort and welfare of neighbours. Kheirabadi (1991) points out that there was a responsibility among traditional families to support the less fortunate neighbours and families by the more fortunate ones and therefore no neighbour would remain in hunger or deprivation. As a result, most residents of the neighbourhood usually know each other. Such type of society and cultural mentality causes more relation between neighbours and consequently improves social interaction and cohesion in neighbourhood.

As a result of such social cohesion inside the neighbourhood, public space can have a great role as a place for social interaction of residents. As mentioned in the previous section, cul de sacs provide a semi-public space which was usually used by neighbours to socialize (Madanipour, 1998). Specifically, women who were spending more time in house and local community (Moser, 1987) were more comfortable to use these blind alleys as a semi-public or semi-private space for meeting and chatting with other neighbours (figure 7). The semi-privacy of these alleys could make them more usable in the cultural context of Iranian community. Moreover, applying environmental solutions, like covered passageways or small shaded space for seating, could make these blind alleys more comfortable for socializing.

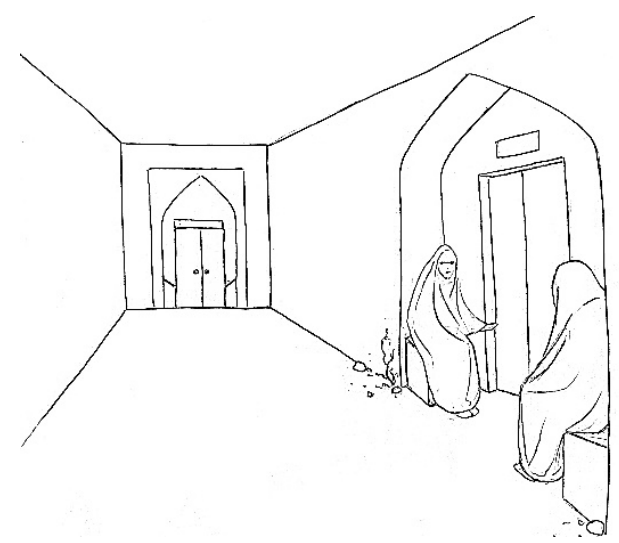

Figure 7. Cul de sac in traditional urban form has provided a semi-private open space which has been usually used by neighbours for socializing

\subsubsection{Adaptation for Contemporary Cities}

As a result of rapid urbanisation in recent decades, the contemporary cities have been filled by a large number of residents with a high variety in ethnicity, religion, or job expertise. This is a new challenge for the cities which turned the cohesive community of traditional neighbourhoods into a new mixture of residents with various backgrounds and interests. As a benefit of such transition, this new shape of community can generally reduce the traditional conflict between different local communities of the city. However, as a disadvantage, the new neighbourhoods do not have as much social cohesion as the traditional ones, hence neighbourhoods may have a lower level of social interaction than the traditional communities.

Another main reason which reduced the social interaction in contemporary cities is the high level of traffic and the speed of vehicles. Barton (2003) indicates that high level of car traffic results in low level of social interaction between neighbours. Consequently, one of the main solutions in order to enhance the social interaction in neighbourhoods is to reduce car traffic.

It has been mentioned that cul de sacs have been the traditional place for social interaction of local residents. Also based on contemporary urban design literature (for example: Barton, 2003), this type of street can reduce the speed and traffic of vehicles. Therefore, it can be emphasized that designing cul de sacs in contemporary cities of Iran can help reduce car traffic and therefore improve social interaction and social cohesion on a neighbourhood scale. However, these new cul de sacs should be designed in a way to encourage residents to use this semi-public space as a meeting space for social interactions.

Some of the contemporary urban design solutions for residential neighbourhoods can be helpful in order to make 
cul de sacs better places for social interaction of neighbours. Some literature (for example: Bentley et al. 1985, Biddulph, 2001) have outlined the benefits of the idea of Home Zone, which has been used regularly in some European countries such as the Netherlands in order to help pedestrians to dominate in residential neighbourhoods instead of cars and consequently making the streets more comfortable for meeting, chatting and even playing for children. The overall urban design principles of home zones can be applied for new cul de sacs in Iranian cities and therefore the traditional benefits of the cul de sacs, as a place for social interaction, can be reinforced by this contemporary design solution. The design solutions which relate to the home zone idea will be applied and demonstrated in design part of the article. However, the main concept is to reduce car dominance in new cul de sacs and encourage residents to use this semi-public space for socializing, hence the social cohesion of Iranian cities can be re-improved.

\subsection{Family and Life Style}

\subsubsection{Family and Life Style in Traditional House and City}

As another characteristic for traditional urban life, literature points out that there has been a widespread tendency for living in extended families (Madanipour, 1998; Roaf, 1997). As a result, the traditional houses normally tend to have a large foot print compared with the contemporary size of the house. Many examples of traditional houses can be found in Iranian cities which contain several rooms and living space which are gathered around two or three courtyards. Moreover, the courtyards tend to be designed in relation to a size which several living spaces can be organised around. As evidence, Roaf (1997) mentions that in the city of Yazd, in the central part of Iran, courtyards are about 10 meters width and 14 meters length. Roaf (1997) states that the usual form of the courtyard in such a hot climate should be deeper and more shaded than this size. However, it can be argued that this large footprint for the courtyard has been designed for the life of extended families.

As a spatial implication of such a lifestyle in extended families and such a large footprint of the house, it can be mentioned that the traditional cities have contained larger plots or, in other words, in comparison with the contemporary urban form, the traditional neighbourhoods had fewer houses of a larger size. Consequently, as is illustrated in figure 8 , in traditional shape of neighbourhoods, there are limited numbers of entrance doors which open to the streets. Therefore, it can be stated that the large footprint of the houses is another reason for limited active edges and limited permeability of the streets.

\subsubsection{Adaptation for Contemporary City}

Madanipour (1998) points out that during the modern era the lifestyle and shape of the Iranian families has been changed from the traditional extended families into the new nuclear shape of the family. Therefore, it can be stated that such new smaller size of families need smaller size of houses and consequently the size of plots and residential buildings in contemporary cities tend to be smaller than the traditional types. As it was mentioned, the traditional houses have relatively large size of court yards which are not appropriate for the contemporary lifestyle but the overall concept and typology of the courtyard housing has many advantages based on the environmental and cultural context of Iranian cities. Therefore, it can be suggested that in order to use the typology of courtyard housing in contemporary urban context, it is required to design smaller size of the courtyard houses.

Despite the fact that courtyard houses should be designed in smaller size, these new courtyards should be designed in a size which provide both the shaded spaces for various uses like seating and also spaces which receive sunlight during the day which are appropriate for planting and vegetation. The design ideas for such new types of small courtyard houses will be proposed in Section Four which is related to inquiry by design part of the research.

As another benefit of these small-sized plots and houses, designing such small-sized plots make more entrance doors in the street with the traditional form of the streets which had few doors and windows; therefore, such small-sized plots can create more active edges for the public spaces that improve the safety of residential neighbourhoods and urban areas. 

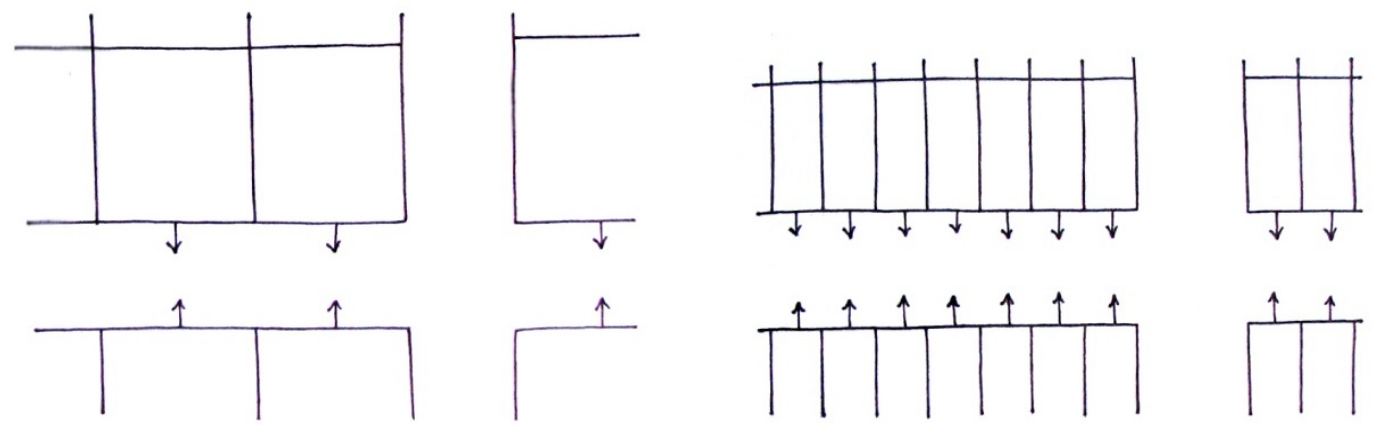

Figure 8. Smaller size of houses can increase number of the entrances which open to the public space and therefore provide more active edges for the street

\section{Testing Theoretical Propositions via Design}

In this stage the theoretical view regarding adaptation of traditional urban form for contemporary use is tested via a process of design. As it discussed in previous part, courtyard housing is one of the best design solutions which can respond to the environmental and cultural condition of Iranian cities. In this design process, carried out by the author, the main goal is to show how it is possible to combine the courtyard houses in multi storeys and reach the sufficient density for the urban areas in contemporary cities. Also as it mentioned that the extended families have turned into nuclear families, it is necessary to make smaller-sized courtyard houses compared with the traditional types.

In the following part (table 1 and figure 9 and 10) the design process of a generic cul de sacs will be demonstrated to show how it is possible to combine the courtyard houses in multi storeys. Three different design alternatives were sketched and finally one of them which could better deliver the above environmental and cultural qualities was selected for this study. 
Table 1. Design process and shape of each floor in the cul de sac

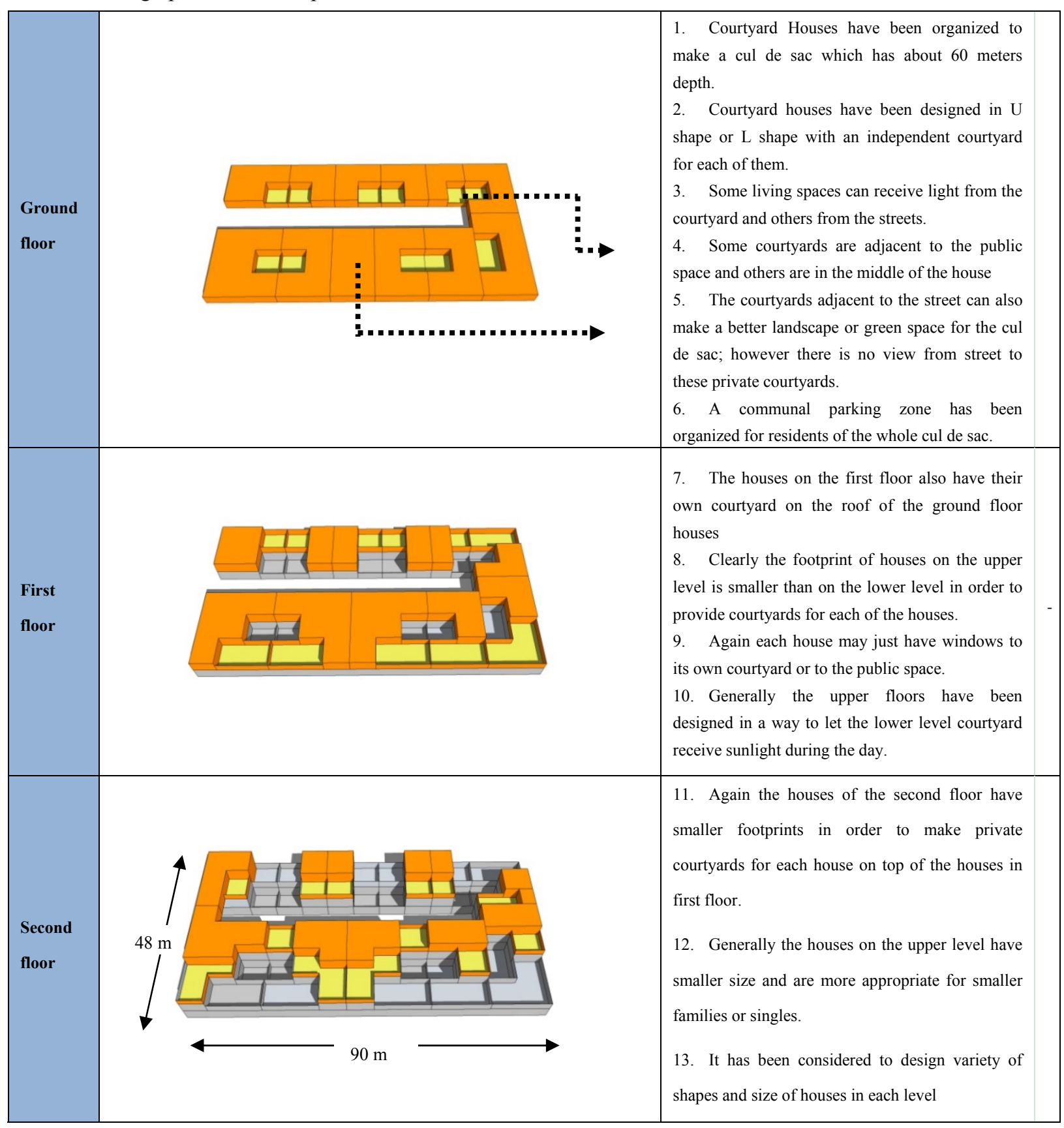




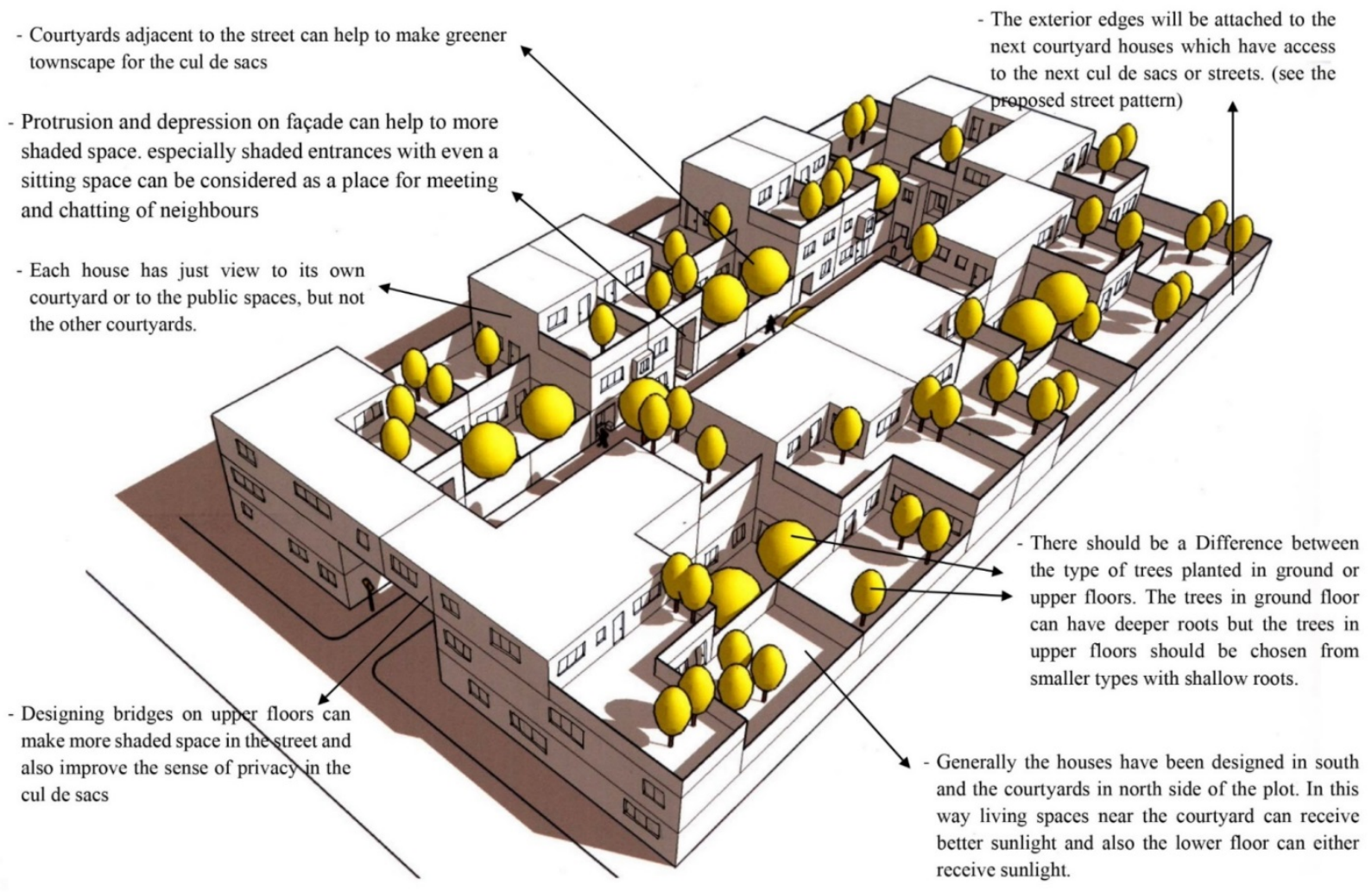

Figure 9. Model of a cul de sac based on the adaptation of traditional urban form

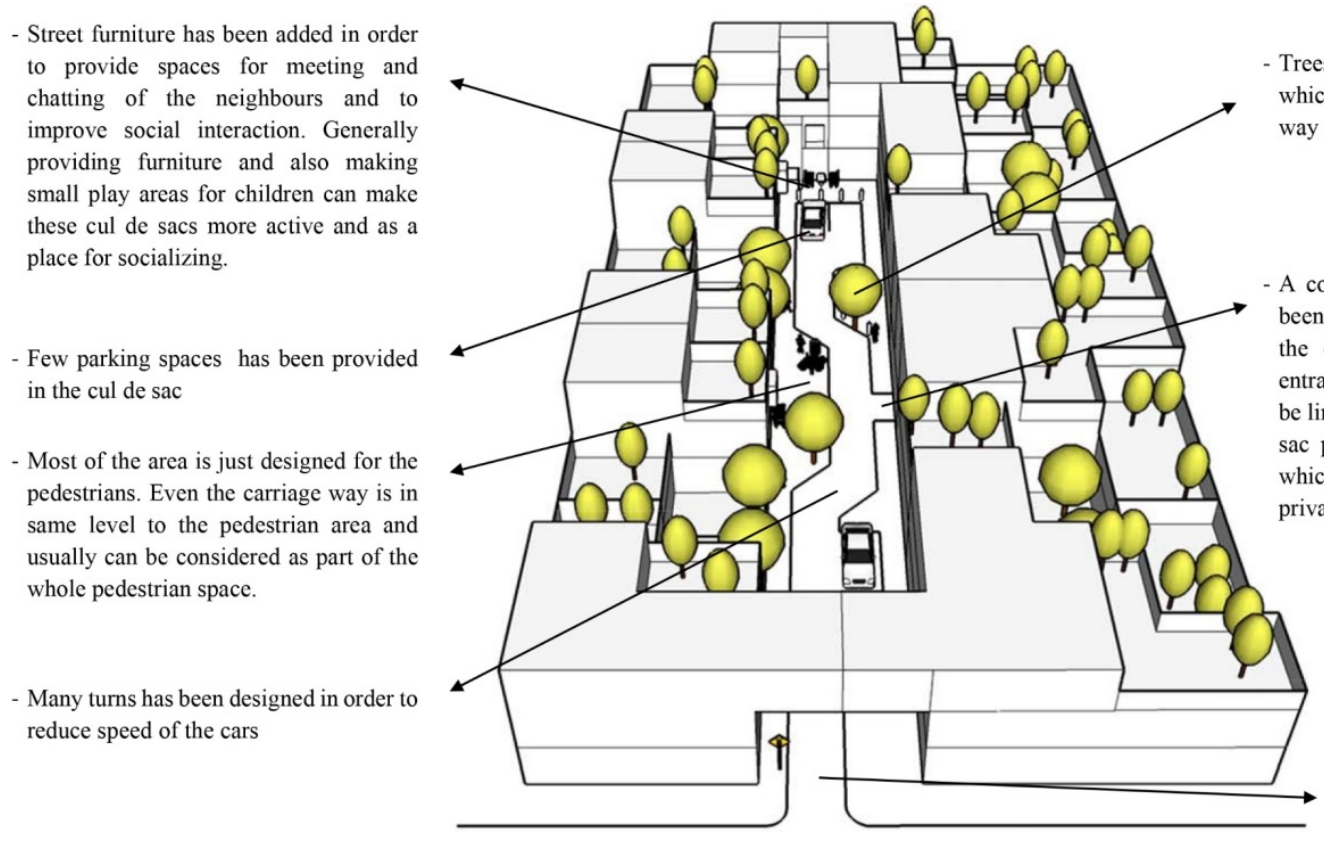

Trees has been located in places which makes turns in the carriage ay and reduce the speed of cars.
Using the sign of home zone or changing the materials of the street can inform the drivers that there is a speed limitation in this area

Figure 10. Shared spaces and street design 


\section{Assessment of the Design Scheme via Focus Group Discussion}

To assess the design proposal, it has been deemed to present the project for participants and to receive feedback or discuss the adequacy of the design proposal. Such a research approach, based on presenting and receiving feedback, can help to understand the advantages and disadvantages of the proposal from different point of views. Therefore, the strengths and weaknesses of the design principles can be assessed from different aspects.

To receive robust feedback, the design proposal was not the only aspect presented to participants, but also the framework, initial principles and design rationales were explained. The focus group contained five participants. Four participants are urban designers but from a variety of backgrounds in architecture and planning fields. The fifth participant was chosen from non-expert people in the fields related to the built environment, but as a married woman who relatively spends most of her time inside the house or in the residential neighbourhood area. It should also be mentioned that all these participants were chosen from Muslim people who lived in Islamic countries and are consequently familiar with the cultural values emphasized in the design rationales and proposal. The participants are from Egypt, Bahrain, Malaysia and two of them from Iran. Moreover, it should be mentioned that four of these participants are from Middle Eastern countries and therefore they are familiar with such hot and dry climate and the overall environmental context in this region of the world.

Through the focus group discussion table 1 and figure 9 and 10 were presented for the participants and the rationales of the design based on environmental and cultural issues were explained. Then they were asked to comment about the success of design scheme and its appropriateness for the Middle Eastern context. The following section explains the overall results of discussions about the design rationales and proposal.

\section{Findings Based on the Focus Group Discussion}

As a fundamental rationale for design proposal, it has been mentioned that due to the need for designing maximum shaded spaces, the open spaces in private or public realm have tended to be designed in a smaller size in comparison with the general size of open spaces in existing contemporary cities. However, one of the points that has been argued in the discussions was that these small open spaces, which will be considered as green space of the city, may not efficiently help to clean the air and reduce the air pollution of the city. It has been debated that separated small scale green spaces cannot respond effectively to the condition of contemporary cities in ecological terms. As a result, it should be stated that it is required to conduct further investigation into the ecological adequacy of such new typologies of urban form. However, it can be initially suggested that larger scale of green open spaces such as parks and public gardens should also be added to the whole scheme of the city in order to respond to the ecological viability of the development.

On the other hand, it has been pointed out that having courtyards for each family, in the same storey which they live, can make more sense of belonging to these private open spaces. Therefore, residents tend to take more care of their own private courtyard and be encouraged to plant in this open space. Consequently, citizens would have more connection to the nature in such new neighbourhoods.

As another feedback on the environmental and cultural aspect of this proposal, it has been stated that some of the houses have a limited number of windows so as not to infringe on the privacy of the courtyards of other houses. (See figure 9) Therefore, some parts of these buildings may not receive sufficient amount of sunlight or natural heat. However, on the other hand, it has been mentioned that these few windows have much better quality than the existing shape of windows in residential flats. These new windows mostly open to the private courtyard and therefore there is no need for these to be covered by curtains; hence these few windows can receive more sunlight and create better views for the living spaces.

Another concern which has been mentioned regarding the privacy issue is that, despite the fact that the courtyards, which have been located near the street, have made a semi-green skyline for public space, as a disadvantage of this design solution, some of these courtyards can be viewed from the houses on the other side of the street. Therefore, this may reduce privacy of these courtyards (see figure 9).

Finally, it has been stated that despite the fact that the design proposal has suggested similarity and simplicity in exterior facades (based on the rationales related to social equity and limited personal expression), such type of design has not created a boring townscape in this new development. The main reason for this circumstance is the variety of forms, volumes and different range of shadow and light in the public spaces. The existing shape of the development in contemporary cities is based on similar cubic forms of flats. These flats have the same shape and form but different textures, materials, details and exterior decoration. Conversely, this new type of design tends to create similarity and unity in the detail of buildings but to make a variety of shapes, volumes, shaded and lighted space on the scale of the whole public realm. 


\section{Conclusion}

The purpose of this study was to make suggestions and define principles on the scale of urban design to make the future urban fabric of Iranian cities more responsive to the environmental context of this specific region of the world. It also aimed to respond to the cultural demands of the local citizens. Therefore, the main outcome has been distinctive urban forms which respond to the local context of the country.

This research tries to propose an overall methodology for understanding the local condition in each specific part of the world and how to make distinctive design ideas relate to that specific local context. In this way, the vernacular architecture of each area of the world can demonstrate the local condition of the region and the traditional design solutions which have responded to the local context for centuries. The research approach of analysing the local traditional architecture and urban form can be repeatedly used in different locations in order to find the specific design principles that respond to each particular local context. The key point is to understand the main rationales and values behind the vernacular architecture and to find contemporary design solutions that respond similarly to such local values and conditions.

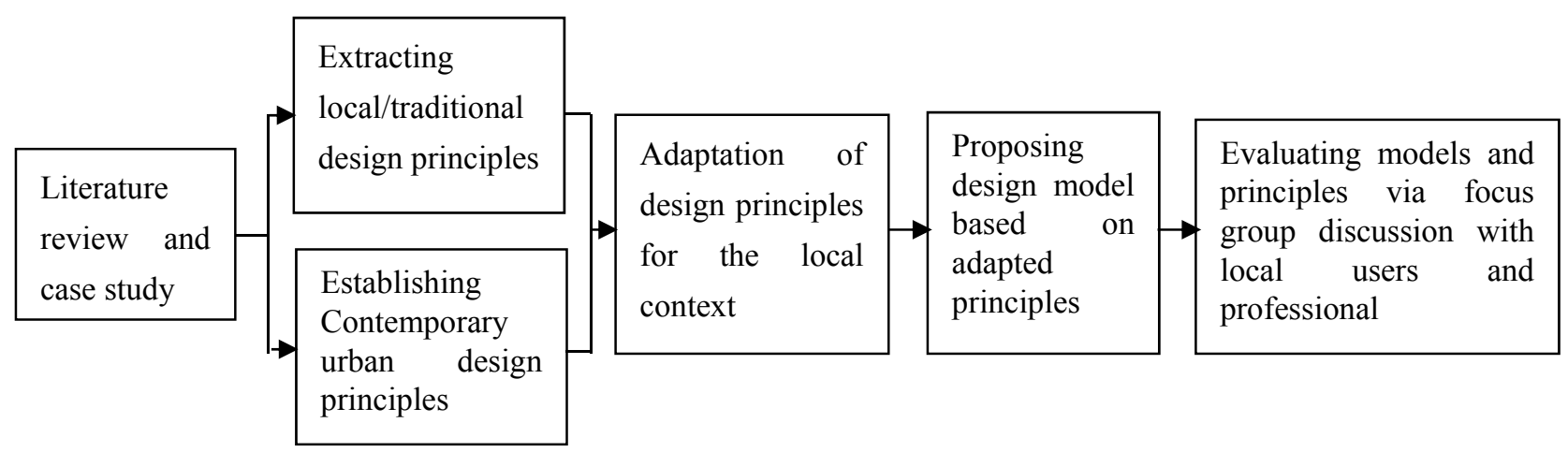

Figure 11. Transferable process of the research

\section{Acknowledgement}

This article is based on the author's Master Degree Dissertation in Urban Design under supervision of Dr. Regina Mapua Lim in Oxford Brookes University, UK.

\section{References}

Barton, H. (2003). Shaping Neighbourhoods. London: Spon Press.

Bentley, I. et al. (1985). Responsive Environments: A Manual for Designers. Oxford: Architectural Press.

Biddulph, M. (2001). Home Zones: A Planning and Design Handbook. Bristol: Policy Press.

Chow, R., \& Chastain, T. (1997). Courtyard: convection cooling. In P. Oliver (Ed.), Encyclopedia of Vernacular Architecture of the World. Cambridge: Cambridge University Press.

Falamaki, M. (1977). An essay on urban conservation: from Venice to Shiraz. Tehran: Aban Publication (in Persian).

Fathy, H. (1986). Natural Energy and Vernacular Architecture: Principles and Examples with Reference to Hot Arid Climates. Chicago: University of Chicago Press.

Ghobadian, V. (1998). Climatic analysis of the traditional Iranian buildings. Tehran: Tehran university press (in Persian).

Habibi, M. (2003). From village to city: Historical analysis of concept of urban and physical aspects. Tehran: Tehran university press (in Persian).

Hakim, B. S. (1997). Rule systems: Islamic. In P. Oliver (Ed.), Encyclopedia of Vernacular Architecture of the World. Cambridge: Cambridge University Press.

Hillenbrand, R. (1994). Islamic Architecture: Form, Function and Meaning. Edinburgh: Edinburgh University Press.

Kheirabadi, M. (1991). Iranian cities, formation and development. Austin: University of Texas Press.

Madanipour, A. (1998). Tehran: the making of a metropolis. Chichester: John Wiley. 
Madanipour, A. (2010). Sustainable Development, Urban Form, and Megacity Governance and Planning in Tehran. In A. Sorensen, \& J. Okata (Eds.), Megacities: Urban Form, Governance and Sustainability. London: Springer.

Moser, C. O. N. (1987). Women, Human Settlements and Housing: A Conceptual Framework for Analysis and policy making. In C. O. N. Moser, \& L. Peak (Eds.), Woman. Human Settlement, Housing. London: Tavistock Publication.

Norton, J. (1997). Courtyard. In P. Oliver (Ed.), Encyclopedia of Vernacular Architecture of the World. Cambridge: Cambridge University Press.

Oliver, P. (1997). Corridor. In P. Oliver (Ed.), Encyclopedia of Vernacular Architecture of the World. Cambridge: Cambridge University Press.

Pirnia, M. (2004). Introduction of Iranian Islamic Architecture. Tehran: Science and Industry University of Iran Press. (in Persian)

Pirnia, M. (2007). Typology of Iranian architecture. Tehran: Soroush Danesh Press (in Persian)

Zamani, B. (2010). The design and development of public open space in an Iranian new town. In A. Madanipour (Ed.), Whose public space? : International case studies in urban design and development. London: Routledge.

\section{Copyrights}

Copyright for this article is retained by the author(s), with first publication rights granted to the journal.

This is an open-access article distributed under the terms and conditions of the Creative Commons Attribution license (http://creativecommons.org/licenses/by/4.0/). 